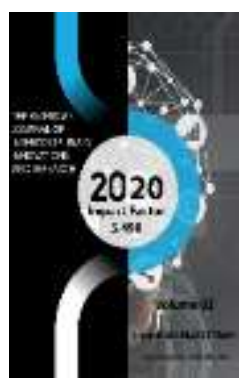

\title{
Pathomorphological Characteristics Of Glandular Hyperplasia Endometry In Women According To The Data Of The Bukhara Regional Pathological Bureau
}

\author{
Zhuraeva Gulbahor Bakhshillaevna \\ Bukhara State Medical Institute Named After Abu Ali Ibn Sina, Uzbekistan
}

Journal Website:

http://usajournalshub.c

om/index,php/tajiir

Copyright: Original content from this work may be used under the terms of the creative commons attributes 4.o licence.

\section{ABSTRACT}

The results of examination of 107 patients with glandular hyperplasia of the endometrium are presented. The age of women ranged from 43 to 67 years, on average it was $41.2+2.6$ years, of which 76 patients were of reproductive age and 49 during the perimenopause. The diagnosis of glandular hyperplasia was established on the basis of morphological scraping of the uterine mucosa. The morphological forms of glandular hyperplasia of the endometrium were analyzed and a comparative analysis of the frequency of all this pathology in the Bukhara region was carried out. The results of the study showed a high growth of this pathology, the cause of which is uterine bleeding, which was confirmed by morphological examination.

\section{KEYWORDS}

Endometrial hyperplasia, neoplasia, precancerous endometrial condition, morphology.

\section{INTRODUCTION}

Glandular hyperplasia of the endometrium $(\mathrm{GBH})$ is a fairly common disease, is the most frequent variant of hyperplastic changes in the uterine mucosa and develops due to hormonal imbalance and excessive intake of folliculin or corpus luteum hormone (progesterone) into the body. The Republic of Uzbekistan is no exception. According to Russian authors, endometrial hyperplasia in the structure of gynecological diseases ranges from 15 to 50\% $[1,3,8]$.

With a prolonged course and no treatment, HPE leads to the development of endometrial cancer, which currently ranks fourth in the structure of malignant neoplasms in women 
and tends to increase $[2,7,10]$. It should be noted that, having an important medical significance, it is a frequent cause of uterine bleeding in perimenopause, limited possibilities of conservative treatment of endometrial hyperplasia due to concomitant diseases, a high recurrence rate (0.25-64.7\%) and the likelihood of malignancy $(0.3-45,1 \%)$ of endometrial hyperplasia. (Kogan E.A., Stanoevich I.V., Kudrina et al. // Arch.pat.-2007.Issue 7.-P.21-24.) [4,5, 3].

Despite the progress achieved in the prevention of this pathology, the issues of assessing the morphological criteria of endometrial hyperplasia and especially atypical hyperplasia are still controversial. Various complications arising from the presence of this pathology such as infertility, miscarriage, reproductive losses, etc. An increase in the frequency of endometrial pathology in the population is noted by many researchers. (Korsak V.S., Zabelkina O.A., Isakova A.A. .)

Unsatisfactory treatment results require new tactical approaches and improvement of gynecological tactics, as well as the development of more effective methods for the prevention of developing complications.

\section{PURPOSE OF THE STUDY}

Timely identification of various morphological forms of endometrial hyperplasia, to improve diagnosis and pathogenetic therapy.

\section{MATERIALS AND METHODS}

The study was carried out on the basis of the Bukhara Medical Institute "Bukhara Pathological Bureau" in Bukhara. Studies were carried out on scraping from the uterine cavity, patients from the gynecological department of the Republican Scientific Center for Emergency Medical Aid of the Bukhara region who were admitted with uterine bleeding. The age of the patients varied from 40 to 54 years and over, the average age of which was $49 \pm 0.5$ years. We also studied the medical history of these patients. The following classification of endometrial hyperplastic processes was used. (Moscow Regional Research Institute of Obstetrics and Gynecology).

\section{Table 1.}

Distribution of patients with endometrial hyperplasia

\begin{tabular}{|c|c|c|}
\hline Age and years & Absolute number & Share in \% \\
\hline $40-44$ years & 36 & 43.6 \\
\hline $45-49$ years & 48 & 21.5 \\
\hline $50-54$ years old and over & 23 & 100 \\
\hline Total & 107 & \\
\hline
\end{tabular}

Also, these patients were distributed by age and age period. 
Table 2.

Distribution of patients with endometrial hyperplasia by age

\begin{tabular}{|c|c|c|}
\hline Period & Absolute number & Share in \% \\
\hline Reproductive & 25 & 23,3 \\
\hline Late reproductive & 28 & 25,6 \\
\hline Premenopause & 37 & 35,3 \\
\hline Postmonopause & 17 & 15,8 \\
\hline Total & 107 & 100 \\
\hline
\end{tabular}

Morphological analysis was carried out using a survey method: For histological examination, the scrapings were fixed in $10 \%$ formalin solution in phosphate buffer and, after dehydration in alcohols, embedded in paraffin. Sections 5-7 $\mu \mathrm{m}$ thick were stained with hematoxylin and eosin to detect various forms. The diagnosis was made on the basis of the results of histological examination using a Leica microscope.

Research results and discussion

The results of morphological studies of biopsy material taken from 107 patients, the first group consisted of 36 patients aged from 40 to 44 years, the second group from 45 to 49 years old, the third group from 50 to 54 and over.

\section{Table 3.}

Complaints of patients with endometrial hyperplasia

\begin{tabular}{|c|c|c|}
\hline Complaints & Amount & Share in \% \\
\hline Dysfunctional uterine \\
bleeding
\end{tabular}


In $39 \%$ of patients, hyperplasia was detected during ultrasound studies.

Table 4 shows gynecological diseases in patients with endometrial hyperplasia. It was noted that $89 \%$ had a history of gynecological disease endocervicosis of the cervix (42.9\%), chronic endometritis (17.7\%), ovarian cysts (14.01\%), uterine myoma (22.4) and acute purulent endometritis ( $2.8 \%)$.

\section{Table 4.}

Gynecological diseases in patients with endometrial hyperplasia (from the history of patients).

\begin{tabular}{|c|c|c|}
\hline Abs. & Amount & Share \% \\
\hline Total & 107 & 42,9 \\
\hline Endocervicosis of the cervix & 46 & 17,7 \\
\hline Chronic endometritis & 19 & 14,01 \\
\hline Ovarian cysts & 15 & 22,4 \\
\hline Myoma of the uterus & 24 & 2,8 \\
\hline Acute purulent endometritis & 3 & \\
\hline
\end{tabular}

The results of a morphological study showed that with endometrial hyperplasia, discirculatory, dystrophic-necrotic and inflammatory changes are noted. (Figure 1). In the stroma, hyperemia and vascular hyperemia in the interstitial space is determined by an inflammatory infiltrate consisting of both neutrophils and lymph-histiocytic cells. 


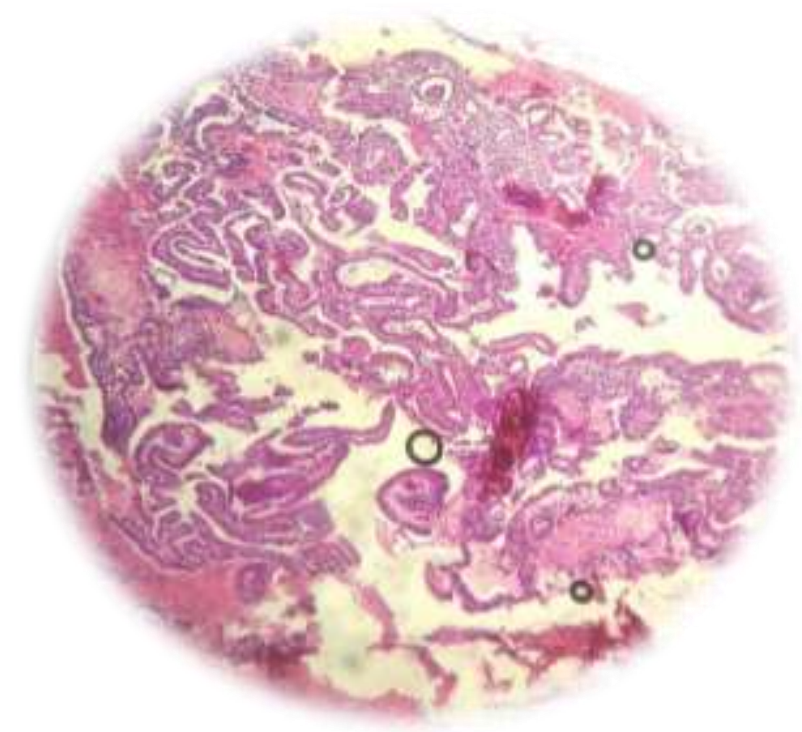

Fig 1. Simple endometrial hyperplasia without atypia. Coloring: H-E. Zoom: about 10, ob. 40.

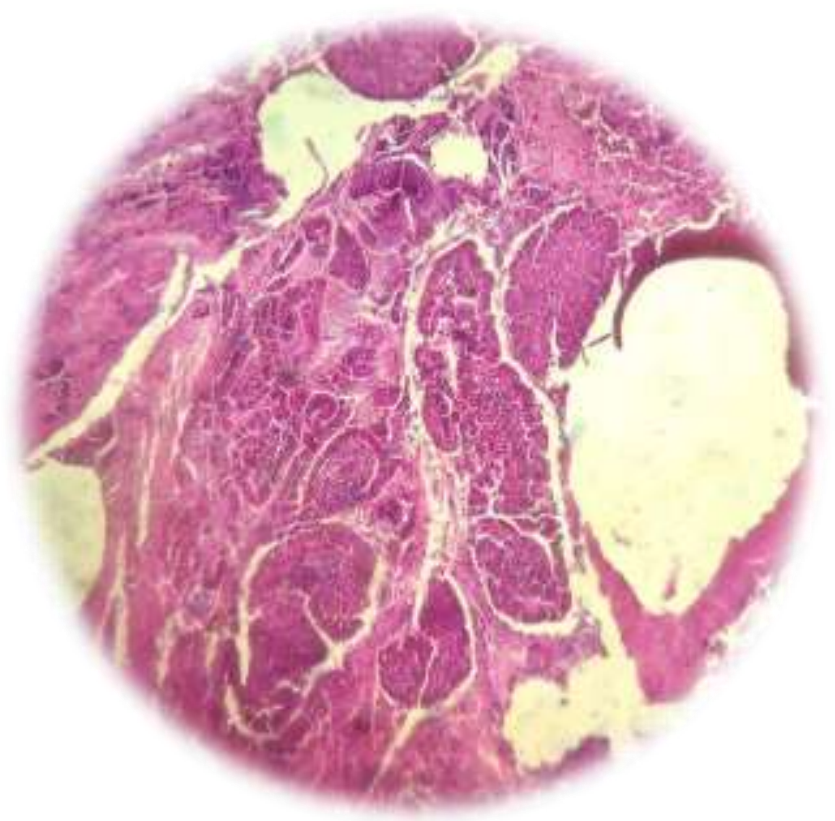

Fig 2. Complex endometrial hyperplasia without atypia, edema and focal inflammation of the interstitium. Color: HE. Zoom: about 10, ob. 40. 
Fig 3. Complex endometrial hyperplasia without atypia, edema and focal inflammation of the interstitium. Color: HE. Zoom: about 10, ob. 40.

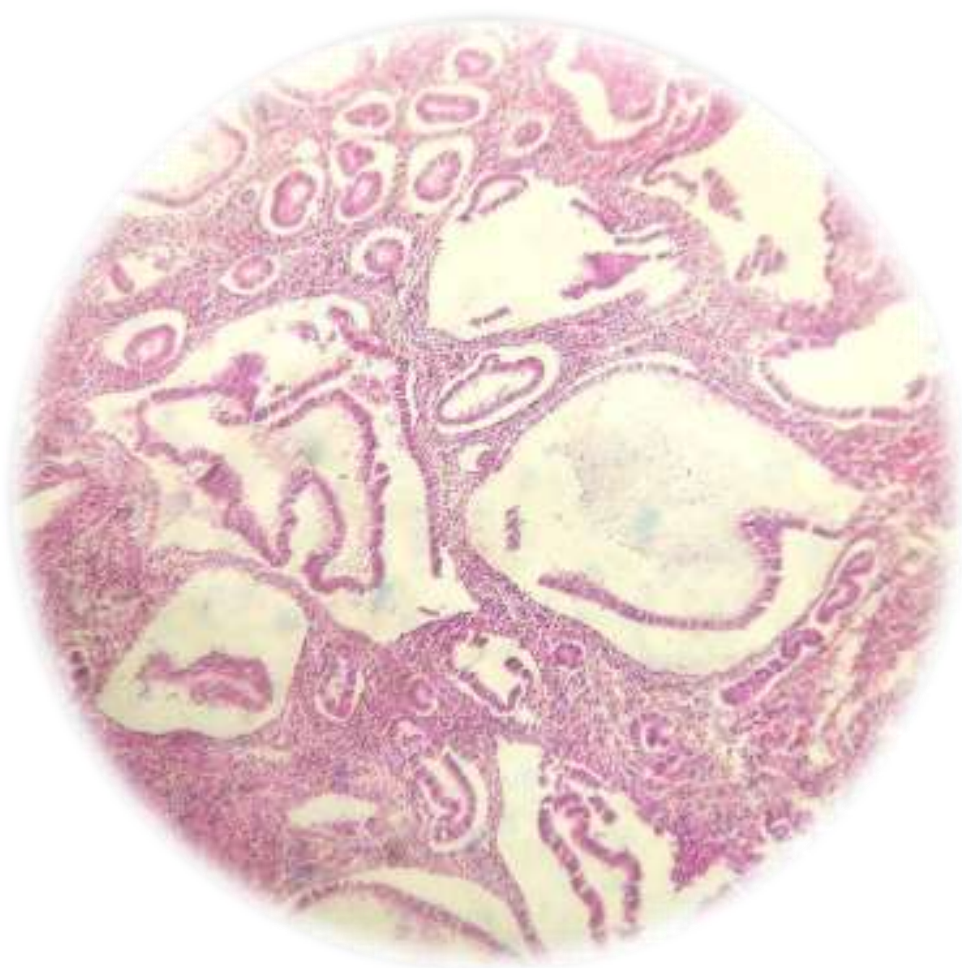

Fig 4. Glandular cystic hyperplasia of the endometrium without atypia, edema and focal inflammation of the interstitium. Color: HE. Zoom: about 10, ob. 40. 


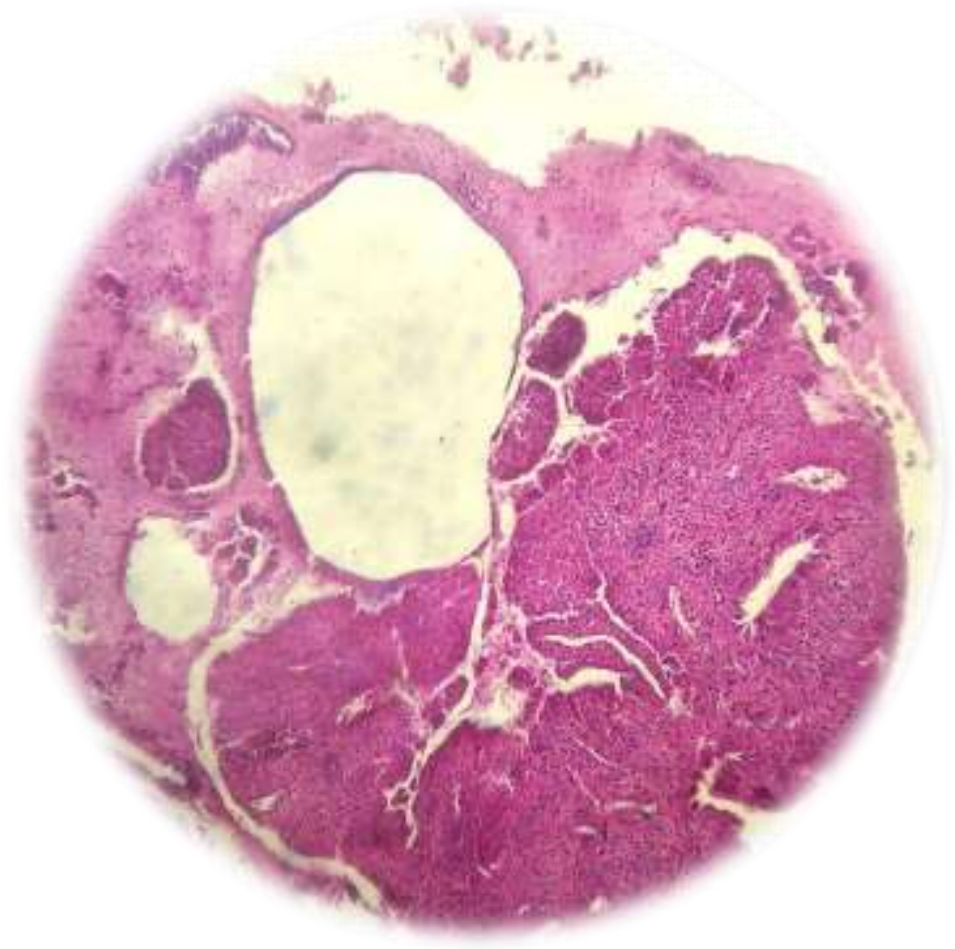

Fig 5. Complex endometrial hyperplasia without atypia, edema and focal inflammation of the interstitium. Color: HE. Zoom: about 10, ob. 40.

\section{SUMMARY}

Thus, our studies have shown that in patients with a diagnosis of endometrial hyperplasia, hyperplasia has significantly increased in recent years.

In terms of the frequency of occurrence of patients with glandular hyperplasia for dyshormonal pathology, simple hyperplasia is inferior to $70 \%$ of cases. Atypical forms are also noted, which can contribute to the development of cancer or malignancy, as complications.

\section{CONCLUSIONS}

1. With endometrial hyperplasia, simple glandular hyperplasia of the endometrium is found in all age groups and is much more common. And complex and atypical endometrial hyperplasia was detected only in 11 women aged 33 to 58 years.

2. In 21 cases, endometrial hyperplasia was combined with chronic endometritis and in 3 cases with acute purulent endometritis, and against the background of these pathologies discirculatory, dystrophicnecrotic, inflammatory changes were revealed and were more pronounced.

3. For the prevention and timely diagnosis of this pathology, an annual clinical examination of women, especially of the elderly and senile age, is necessary with the combined use of hysteroscopy and morphological examination of the material. 


\section{REFERENCES}

1. Adamyan T.V. Diagnostics and surgical hysteroscopy in gynecology: method.recommendations.-M., 1997.

2. Ailamazyan E.K. Dysfunctional uterine bleeding in perimenopause. Gynecology from puberty to postmenopause. -2004. C.316-321.

3. Breusenko V.G., Savelyeva G.M., Head Y.A., Treatment of hyperplastic processes of the endometrium in peri and postmenopausal women // Obstetrics and gynecology.2009.-№4-C.19-23.

4. Bokhman Ya.V., Pryanishnikov V.A., Chepik O.F. Complex treatment for hyperplastic processes and endometrial cancer. - $M$.: Medicine, 1979 .-- 272 p.

5. Bokhman Ya.V., Chepik O.F., Serov S.F., Slepykh A.S. Hyperplastic processes and endometrial cancer // Midwife. gin. - 1974. Issue. 4. - S. 19-22.

6. Gulieva Z.S., Gerasimov A.M., Peretyatko L.P. Structural and functional features of endometry in women with early loss of pregnancy in anamnesis with undifferentiated connective tissue/l Modern problems of science and education. - 2014. - No. 6 .;

7. Kondrikov N.I. Structural and functional bases of hyperplastic changes in the endometrium: Author's abstract. dis. Doctor of Medical Sciences.-M. 1991.

8. Kogan E.A., Stanoevich I.V., Kudrina E.A. et al. Morphological and immunohistochemical parallels in endometrial hyperplasia .- // Arch.path.2007.-Issue 7-P.-21-24 ...

9. Kuznetsova I.V. Hyperplastic processes of the endometrium.M.2009.-47s
10. Pronin S.M., Novikova E.G. Diagnostics and treatment of primary endometrial cancer // Russian Journal of Oncology.-2003.-No.5.P.-19-23.

11. Silverberg S.G. Problems in differential diagnosis of endometrial hyperplasia and carcinoma // Mod. Pathol. - Vol. - P. 309327.

12. Silverberg S.G., Kurman R.J. Atlas of Tumor Pathology // Tumors of the Uterine.

13. Tallini G., Vanni R., Manfioletti G. et al. HMGIC, HMGI (Y) im munoreactivity with cytogenetic abnormalities in lipomas, pulmonary chondroid hamartomas, endometrial polyps and uterine leiomyomas and its compatible with rearrangements of the $\mathrm{HMGIC}$ and $\mathrm{HMGl}$ (Y) genes // Lab.Invest. - 2000. - Vol. 80. P. 359-369.

14. Tashiro A.V., Isacson C., Levine R. et al. P53 gene mutations are com mon in uterine serous carcinoma and occur early in their pathogenesis // Amer. J. Pathol. - 1997. Vol. 150. - P. 177-185.

15. Thor A.V., Viglone M.J., Murero R. et al. Monoclonal antibody $\mathrm{B} 72$ reactivity with human endometrium // Int. J. Gynecol.Pathol. - 1987. - Vol. 6. - P. 235247.

16. Winkler B., Alvarez C., Richart R.M., Crum C.H. Pittfalls in diagnosis endometrial hyperplasia // Obstet. Gynecol. - 1984. Vol. 56 - P. 403-412.

17. Zheleznov B.I. Precancerous changes in the cervix and endometrium // Arch. pat. - 1972. - Issue. 5. - S. 1-7. 